\title{
SPRING MIGRATION OF BALD EAGLES NEAR SASKATOON
}

JON M. GERRARD and P. NAOMI GERRARD, Box 113, R.R. 1, Headingley, Manitoba. ROH OJO

An estimated 11,600 Bald Eagles summer along the shores of the lakes and rivers of northern Saskatchewan. ${ }^{1}$ Virtually all of these eagles winter in the western half of the United States. ${ }^{2}$

Each spring heralds the return of these eagles from their months in the south. This article discusses the spring Bald Eagle migration in the vicinity of Saskatoon based on our personal observations in 1981, and on data compiled from observations by members of the Saskatoon Natural History Society for the period 1960 to 1975.

\section{Methods}

We reviewed 311 Saskatoon area Bald Eagle spring observations made by members of the Saskatoon Natural History Society during the period 1960 through 1975. The earliest spring sighting was 11 March, the latest 6 May. For each sighting, the following information was available in most but not all cases: 1) the maturity of the eagle (adult with white head and tail, or immature), 2) whether the bird was flying or perched and, if flying, the direction of flight, 3) the location of the sighting and 4) the time of day.

Weather records for 1967 through 1975 were obtained from the Monthly Meteorological Summary from the Atmospheric Environment Service, Environment Canada. Since most Bald Eagle migration occurs when the temperature is at or near the daily maximum and since the maximum daily temperature indicates warming and cooling trends, we used maximum daily temperature to assess the influence of temperature on migration following the example of Haugh. ${ }^{3}$ Winds from 0900 to 1500 hours were used to assess the influence of wind on the eagle migration, again following the example of Haugh. ${ }^{3}$ Winds were assigned a direction using 16 compass points S, SSW, SW, etc. When the wind changed more than $90^{\circ}$ during the day it was called a variable wind and was not used in the analysis. Birds were considered migrating if they moved consistently in one direction.

For comparison of available migration weather with weather chosen by eagles to migrate, we used data for the period 20 March to 20 April only for the years 1967 through 1975. Thus the statement that 3.2 eagles/day were seen migrating on SSW winds means that from 20 March to 20 April, an average of 3.2 eagles were seen migrating per day with SSW winds.

Since this 16 year review of spring migration data provided only a random sampling of the eagle migration through the Saskatoon area, we spent 14 days in 1981 (29 March to 11 April) in the vicinity of Saskatoon watching the spring eagle migration and sighted 59 Bald Eagles. Specific notes was kept of roost sites. Whenever possible eagles were followed by car after they left their roost, to document the routes they took and their style of migration. Statistical comparisons were performed using the $X^{2}$ test.

\section{Results}

a) Timing of the migration

Bald Eagles migrate through the Saskatoon area in March and April with 
Table 1. TIMING OF THE SPRING MIGRATION OF BALD EAGLES THROUGH SASKATOON

\begin{tabular}{|c|c|c|c|}
\hline Dates & $\begin{array}{r}\text { No. Adults } \\
(\%)\end{array}$ & $\begin{array}{c}\text { No. Immatures } \\
(\%)\end{array}$ & $\begin{array}{l}\text { Total } \\
(\%)\end{array}$ \\
\hline Mar. 7-11 & $1 \quad(1)$ & $0 \quad(0)$ & $1(<1)$ \\
\hline Mar. 12-16 & 1 (1) & $0 \quad(0)$ & $1(<1)$ \\
\hline Mar. 17-21 & 3 (2) & 1 (2) & 4 (1) \\
\hline Mar. 22-26 & $24(13)$ & $3 \quad(5)$ & $27 \quad(9)$ \\
\hline Mar. 27-31 & $35(18)$ & $3 \quad(5)$ & $45(14)$ \\
\hline April 1-5 & $39(20)$ & $6 \quad(9)$ & $64(21)$ \\
\hline April 6-10 & $53(28)$ & $16(25)$ & $85(27)$ \\
\hline April 11-15 & $34(18)$ & $23(35)$ & $63(20)$ \\
\hline April 16-20 & $2 \quad(1)$ & $3 \quad(5)$ & 9 (3) \\
\hline April 21-25 & $0 \quad(0)$ & $7(11)$ & $7 \quad$ (2) \\
\hline april 26-30 & $0 \quad(0)$ & $1 \quad(2)$ & $1(<1)$ \\
\hline May 1-5 & $0 \quad(0)$ & 2 (3) & $3(1)$ \\
\hline May 6-10 & $0 \quad(0)$ & $0 \quad(0)$ & $1(<1)$ \\
\hline TOTALS & 192 & 65 & 311 \\
\hline
\end{tabular}

Table 2. HOURLY TIMING OF THE SPRING MIGRATION

Time of day

0600-0659 hrs. 0700-0759 hrs. 0800-0859 hrs. 0900-0959 hrs. 1000-1059 hrs. $1100-1159$ hrs. $1200-1259 \mathrm{hrs}$. 1300-1359 hrs. 1400-1459 hrs. 1500-1559 hrs. 1600-1659 hrs. 1700-1759 hrs. 1800-1859 hrs. 1900-1959 hrs.

TOTALS

\section{Number of bald eagles seen perched (\%)}

$\begin{array}{rr}10 & (16) \\ 5 & (8) \\ 4 & (6) \\ 1 & (2) \\ 2 & (3) \\ 1 & (2) \\ 2 & (3) \\ 2 & (3) \\ 0 & (0) \\ 0 & (0) \\ 0 & (0) \\ 13 & (20) \\ 19 & (30) \\ 5 & (8)\end{array}$

64

\section{Number of bald eagles seen migrating (\%)}

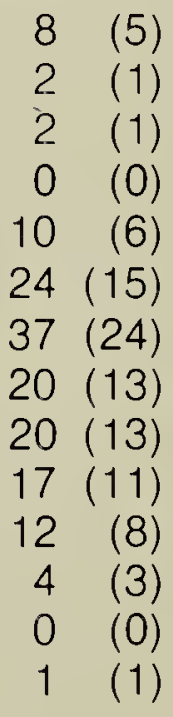

157 
Table 4. BALD EAGLE MIGRATION AND THE CHANGE IN THE MAXIMUM DAILY TEMPERATURE OVER THE PREVIOUS 24 HOURS

Change in the maximum daily temperature

Increase

Decrease

No change

\author{
No. of eagles seen \\ migrating
}

91

33
No of days

(20 March to

20 April '67-75)

153

113

22 rare sightings in early May (Table 1). The mid-date for adult Bald Eagle observations was 5 April $(16 \%$ by 29 March, $84 \%$ by 12 April). Immatures were generally a little later than adults with the mid-date being 12 April (16\% by 3 April, $84 \%$ by 18 April). Migratory movement was observed as early as 0630 hours and as late as 1900 hours. However, most migratory Bald Eagles $(89 \%)$ were seen between 1000 hours and 1700 hours with a peak (24\%) from 1200 to 1300 hours. Most Bald Eagles seen before 1000 hours and after 1700 hours were perched and not migrating (Table 2). Similarly, in 1981, most eagles began their flights between 1000 and 1100 a.m.

\section{b) The influence of weather on migration}

Maximum daily temperatures during days when Bald Eagles were migrating were usually between 0 and $14^{\circ} \mathrm{C}$ (Table 3). Migration was more likely on days when the maximum temperature had risen above that of the previous day (Table 4). Even though the maximum daily temperatures were usually above freezing, most Bald Eagles (90\%) were seen in the Saskatoon area in spring when there was still snow on the ground and $31 \%$ were seen at a time when there was $12 \mathrm{~cm}$ or more snow.

Winds appeared to influence eagles migration. It occurred mostly on SSW winds ( 3.2 eagles per day) and frequently on $S$ winds (1.5 eagles per day). While eagles were seen migrating when winds were in almost all directions, all other winds together averaged only 0.27 eagles per day. The difference between $S$ and SSW winds and all other winds is significant (probability less than 0.01). Interestingly, 50 eagles were seen migrating in 46 days during 1967-1975 with SSW, SW and WSW winds while only 1 Bald Eagle was seen migrating in 31 days with SSE, SE and ESE winds.

Table 3. INFLUENCE OF MAXIMUM DAILY TEMPERATURE ON BALD EAGLE MIGRATION

Maximum daily temperature ${ }^{\circ} \mathrm{C}$

-20 to -16

-15 to -11

-10 to -6

-5 to -1

0 to +4

+5 to +9

+10 to +14

+15 to +19

+20 to +24
No. of Bald Eagles seen migrating

0

0

6

June 1982. 40(2) 


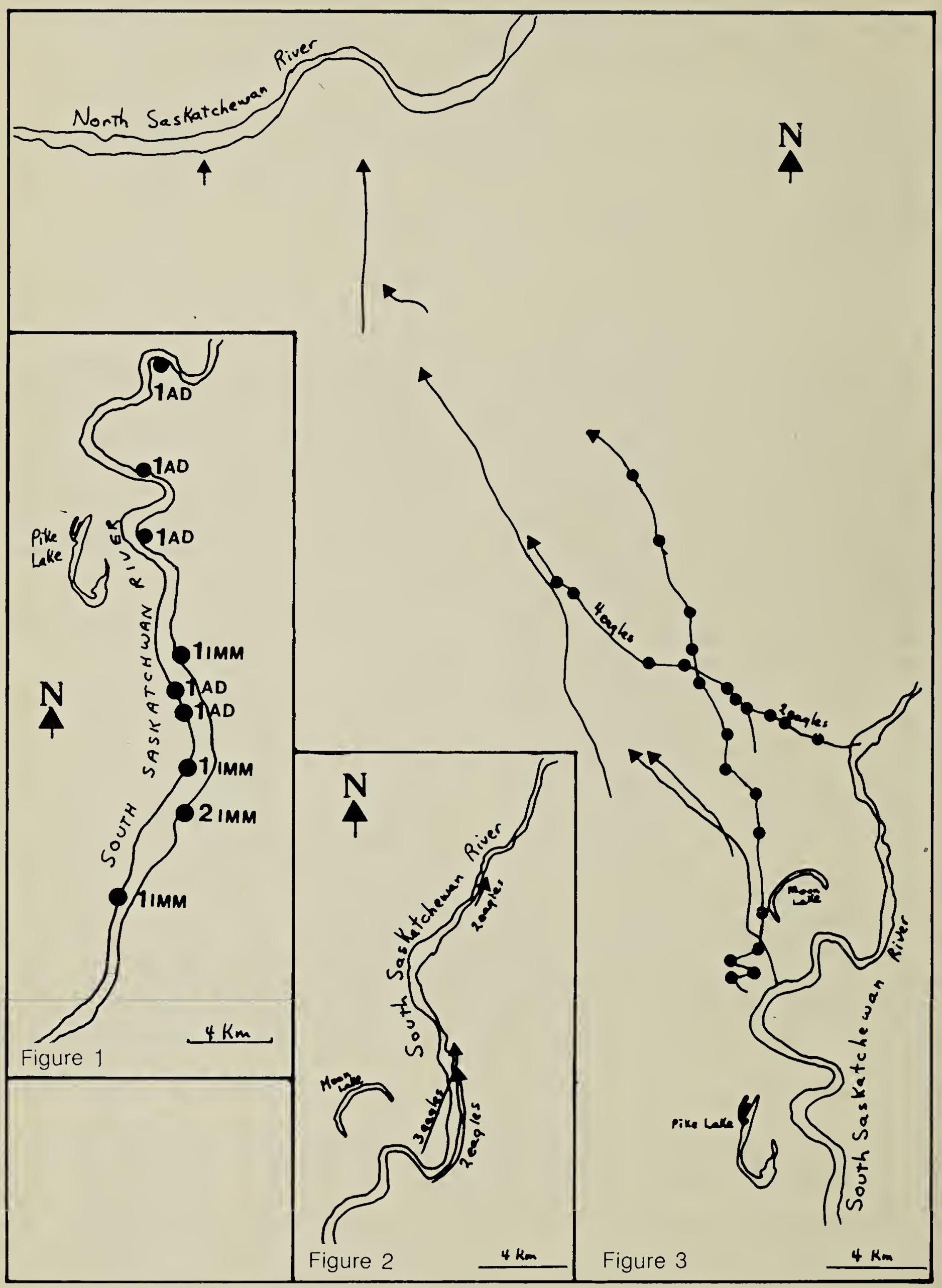

Figure 1. Locations of eagles perched along the South Saskatchewan River on April 2, 1981. The eagles were mostly singles spaced 1 to several kilometers apart.

Figure 2. Eagle movement along the South Saskatchewan River on April 7, 1981. There was a strong west wind and most birds were using updrafts immediately above the river bank.

Figure 3. Eagle migration April 4, 5 and 8, 1981. Paths of 11 Bald Eagles are shown. For two routes, the locations of thermals used by the eagles are shown as the solid circles. 


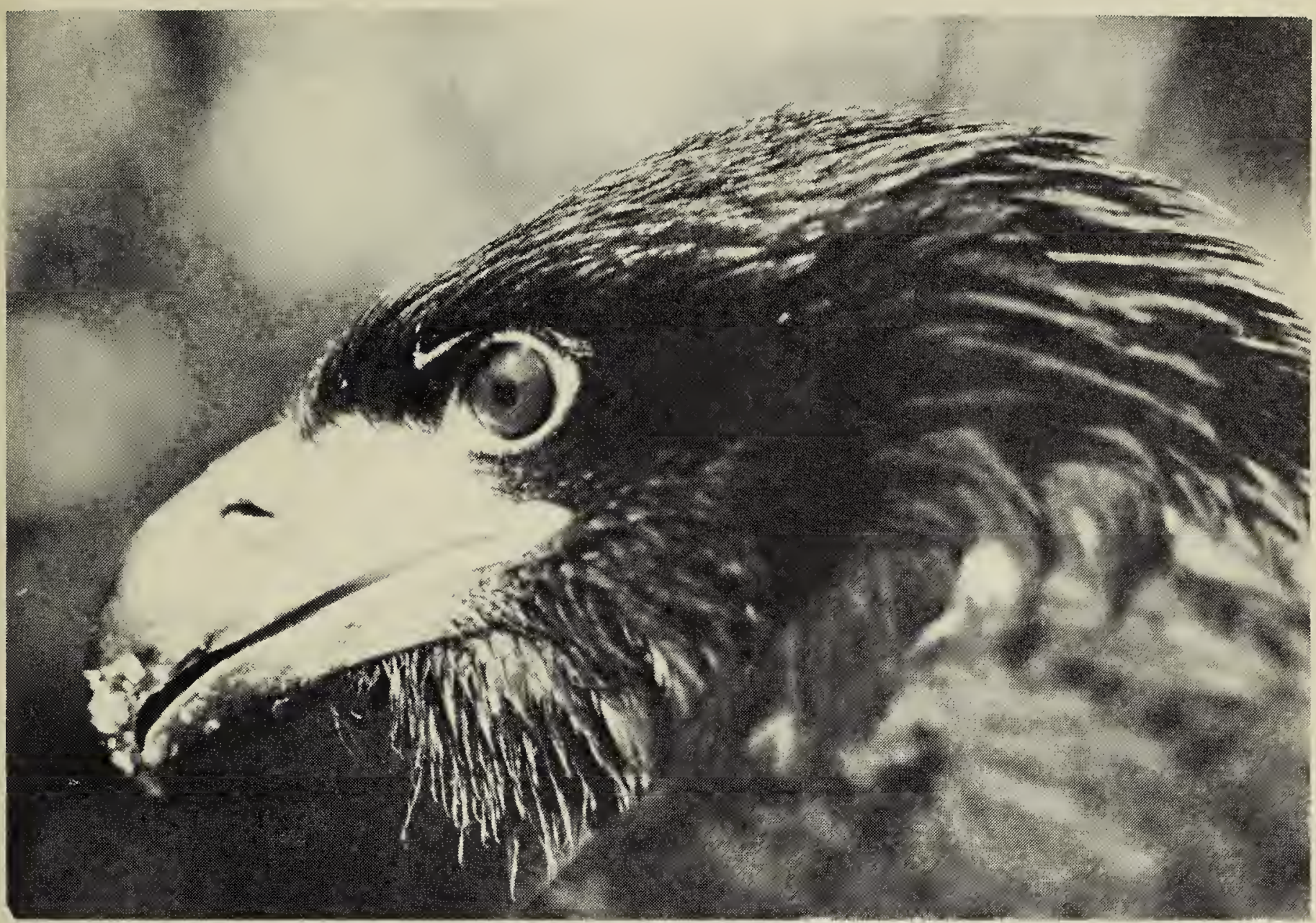

Immature Bald Eagle

Wayne Lynch

When winds had any westerly component, 46 of 70 Bald Eagles seen migrating were seen on the east side of the Saskatchewan River. In contrast when winds had any easterly component, 25 of 33 Bald Eagles seen migrating were seen on the west side of the river. The difference in this distribution is significant $(p<0.01)$.

In 1981 eagles stayed perched along the river all day when the sky was completely overcast and clouds were low. In contrast, when the sun was shining, eagles travelled on any wind.

\section{c) Topography}

Topography appears to influence the path chosen by eagles for migration. The South Saskatchewan River is critical for eagles migrating through the Saskatoon area, for almost all roosting sites were within its valley. As an example Figure 1 shows the distribution of eagles perched along the river on 2 April 1981.
While eagles migrated along the river on some days (see Figure 2), on most days they travelled away from the river. Figure 3 shows the paths of 11 eagles on three days in 1981. The routes taken suggest a migration corridor a few miles wide. Within this corridor the land is not quite as flat as farther northeast and there are more trees.

\section{d) The Style of Migration}

Bald Eagles used three methods of migrating. The most common was to soar up in a thermal and then glide down to another thermal (Figure 4-A). With south winds eagles sometimes continually circled, moving north as they did so (Figure 4-B). On one day in 1982, when there was a strong west wind, eagles moved north along the east bank of the river gliding continually in updraughts (Figure 4-C). Flapping flight was used rarely, primarily to find the first thermal of the day. Occasionally, if an eagle did not arrive at a thermal at the 

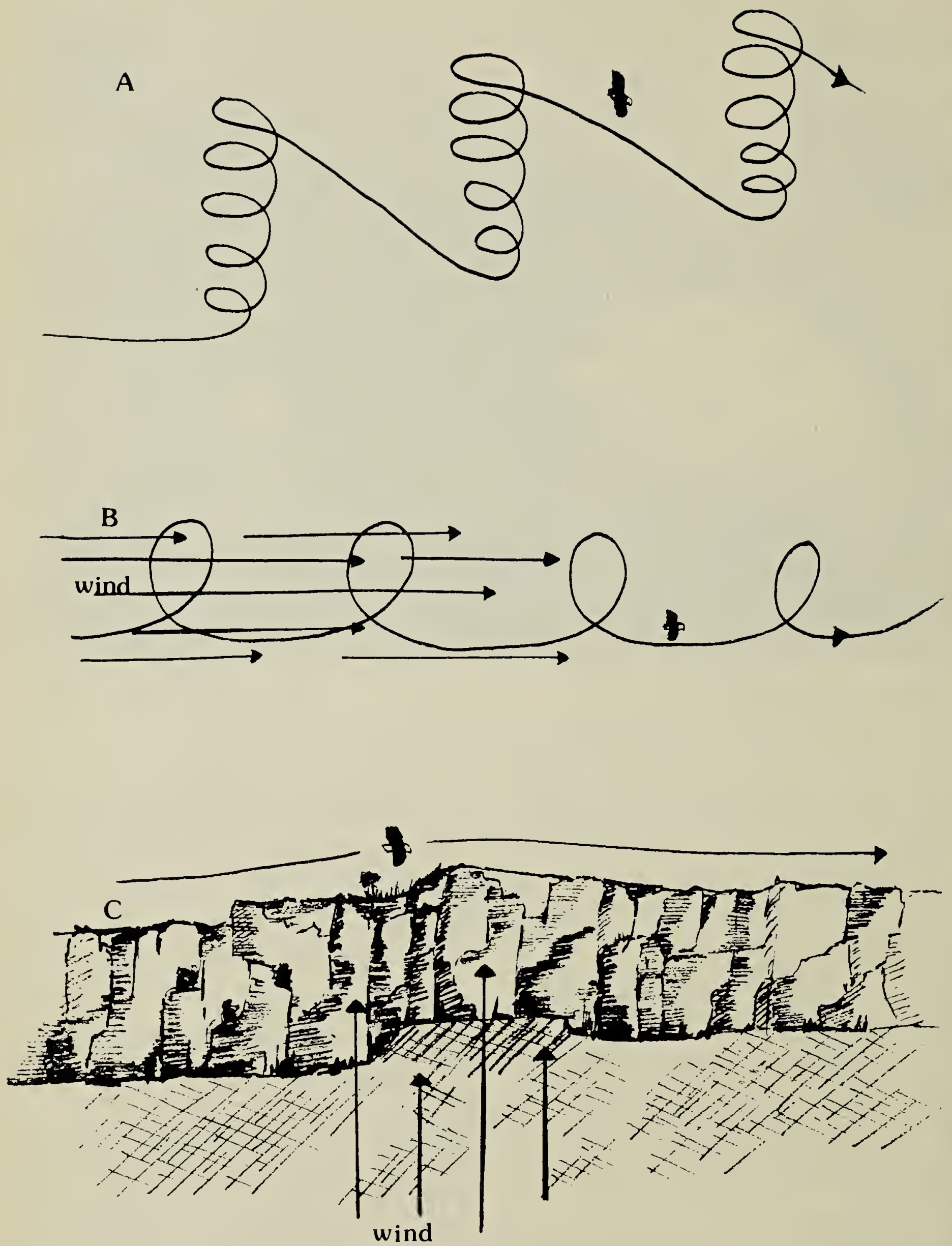

Figure 4. Patterns of eagle migration. When travelling into the wind, and sometimes when travelling crosswind or downwind, eagles gained height by soaring in a thermal then glided on to the next thermal (A). Sometimes, when travelling with a following wind, eagles were seen circling steadily drifting downwind as they did so (B). On April 7, when travelling along the river, the eagles used updrafts created by the wind heading in toward the river bank $(C)$. Flapping flight was observed rarely, being reserved for use in reaching the first thermal, or occasionally when an eagle reached the bottom of a glide without having found the next thermal. 
end of its glide, it was forced to flap until it found the next thermal. Of two birds timed on different days, the first adveraged 150 seconds climbing (soaring) in each of seven consecutive thermals (range 110-230 seconds), while the other averaged 153 seconds climbing in each of 9 such thermals (range 40-270 seconds). The first bird averaged 196 seconds in each of 7 glides between thermals (range 120370 seconds) while the second averaged 154 seconds in such glides (range 45-490 seconds). There was a tendency to climb higher and farther as the day progressed and as thermals became stronger. It is possible that these times are only typical of the early thermals between 1000 and 1200 hours.

\section{e) The Speed of Migration}

One eagle travelling into a light wind covered $29 \mathrm{~km}$ in $70 \min (25 \mathrm{~km} / \mathrm{hr})$. Two others travelling together into a light wind covered $17 \mathrm{~km}$ in $38 \mathrm{~min}(27$ $\mathrm{km} / \mathrm{hr}$ ). One eagle travelling with a light following wind covered $12 \mathrm{~km}$ in $22 \mathrm{~min}$ $(33 \mathrm{~km} / \mathrm{hr})$.

\section{Discussion}

This study expands on earlier observations of raptor migrations through the Saskatoon area in spring. ${ }^{4}$ This spring eagle migration coincides with the beginning of mid-day temperatures just above freezing, with considerable snow still on the ground. In accord with observations elsewhere, adults move northward about one week earlier than immatures, presumably because of the need of adults to set up territories and begin incubation. Migration usually starts between 1000 and 1100 hours and occurs on all sunny days when thermals (rising columns of air caused by differential solar heating of the layer of air above the ground) are generated. On overcast days there is no migration, a finding also made in studies of eagles migrating from Colorado to
Saskatchewan by Al Harmata (personal communication). Migration was most frequent when the maximum daily temperature rose above that of the previous day, and on days when the winds were from the south and southwest. These results agree with John Haugh's in his study of hawk migration. ${ }^{3}$ However, our finding that migration was more frequent on southwest winds than on southeast winds differs from Haugh's observations of the spring hawk migration at Derby Hill at the eastern end of Lake Ontario. The results may reflect a real difference in the choice of winds by Bald Eagles, or more likely, based on experience in 1981, may have reflected the presence of fewer observers on the west side of the river where Bald Eagles may tend to travel on southeast winds.

The South Saskatchewan River valley provides roosting sites for migrating eagles. In spring migration is oriented with respect to these roosting sites. On any easterly wind, eagles appear to leave the South Saskatchewan River valley (which travels from southwest to northeast in the Saskatoon area), and may move away from the river. For their route they chose land which was slightly rolling and with more trees, and avoided where possible completely flat farmland area with few trees. These findings agree with observations of Malmberg in Sweden that birds of prey tend to follow forested areas and avoid cultivated plains. ${ }^{5}$ Observations of migrating eagles in 1981 suggested that slight irregularities in terrain were associated with better thermals earlier in the day than completely flat and open farmland.

When winds had a westerly component, Bald Eagles were more likely to migrate on the east side of the South Saskatchewan River. This suggests that Bald Eagles, like other raptors, are subject to some "downwind drift" from their precise line of migration. The role of west winds in 
"holding" Bald Eagles along the South Saskatchewan River is emphasized in the migrations seen in 1970 and 1971 . In 1970, from 29 March to 10 April there were 13 consecutive days without a wind with an easterly component between 900 and 1600 hours. During this period 36 Bald Eagles were seen in the Saskatoon area. In 1971, from 3 April to 16 April, during another period without wind with an easterly component lasting 14 days, 45 Bald Eagles were seen in the Saskatoon area. No other periods of similar duration without easterly winds occurred during the eagle migration in the years that the weather was carefully evaluated (1967-1975). In all other years, 1967 through 1975, only in 1969 were there as many eagles seen in the Saskatoon area in a comparable period of time (39 Bald Eagles in 10 days).

\section{Acknowledgements}

We thank J. B. Gollop for his help in assembling the records of the Bald
Eagles seen in the Saskatoon area, many of which were his own sightings. We also thank C. S. Houston for helpful comments on the manuscript.

LEIGHTON, F. A., J.M. GERRARD, P. GERRARD, D. W. A. WHITFIELD, and W. J. MAHER. 1979. An aerial census of Bald Eagles in Saskatchewan. Jour. Wildl. Mgmt. 433: 61-69.

2 GERRARD, J. M., D. W. A. WHITFIELD, P. GERRARD, P. N. GERRARD, and W. J. MAHER. 1978. Migratory movements and plumage of sub-adult Saskatchewan Bald Eagles. Can. Field-Nat. 92 : 375-382.

${ }^{3}$ HAUGH, J.R. 1972. A study of hawk migration in eastern North America. Search Agriculture 2: 1-59.

${ }^{4}$ GOLLOP, J.B. Visible migration Saskatoon, 1966. Blue Jay 25: 20-22.

${ }^{5}$ MALMBERG, T. 1955. Topographical concentration of flight lines. Acta XI Congr. Intnatl. Ornith. Basel. 161-164.

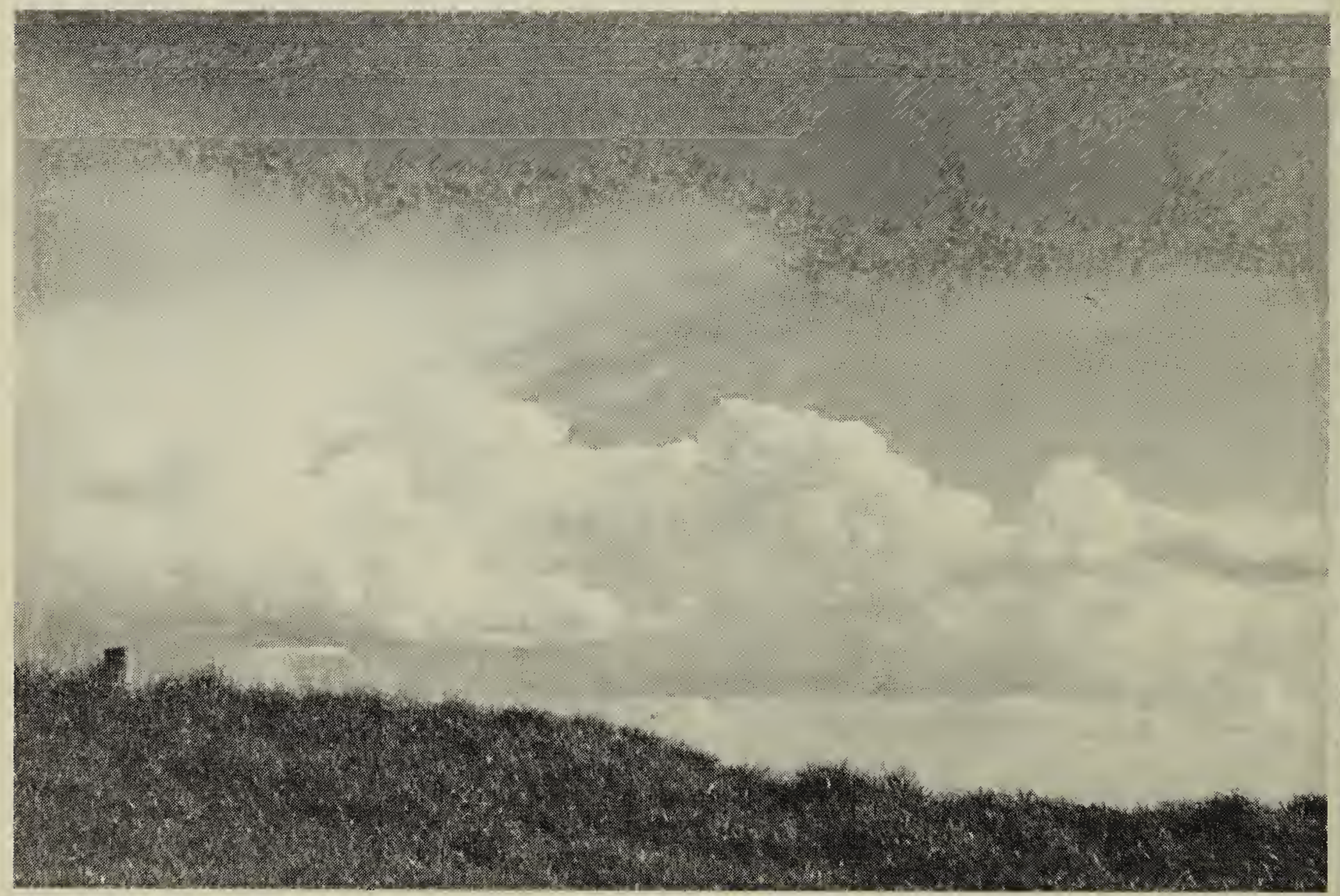

